\title{
Diabetes and Its Treatment Quality in Benin (West Africa): Analysis of Data from the STEPS Survey 2015
}

\author{
Mohamed Lamine Dramé ${ }^{*}$, Carmelle Mizéhoun-Adissoda², Salimanou Amidou², \\ Paulin Sogbohossou ${ }^{3}$, René Paré ${ }^{3}$, Armand Ekambi ${ }^{3}$, Corine Houehanou ${ }^{2}$, Dismand Houinato², \\ Karel Gyselinck ${ }^{3}$, Michael Marx ${ }^{4}$, Maria Rosàrio Oliveira Martins' ${ }^{1}$, Paulo Ferrinho1
}

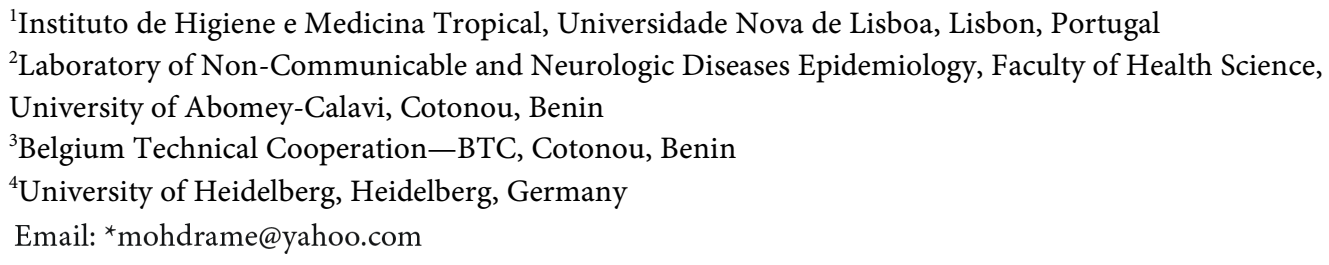

How to cite this paper: Dramé, M.L., Mizéhoun-Adissoda, C., Amidou, S., Sogbohossou, P., Paré, R., Ekambi, A., Houehanou, C., Houinato, D., Gyselinck, K., Marx, M., Martins, M.R.O. and Ferrinho, P. (2018) Diabetes and Its Treatment Quality in Benin (West Africa): Analysis of Data from the STEPS Survey 2015. Open Journal of Epidemiology, 8, 242-258.

https://doi.org/10.4236/ojepi.2018.84019

Received: October 20, 2018

Accepted: November 25, 2018

Published: November 28, 2018

Copyright $\odot 2018$ by authors and Scientific Research Publishing Inc. This work is licensed under the Creative Commons Attribution International License (CC BY 4.0).

http://creativecommons.org/licenses/by/4.0/

cc) (i) Open Access

\begin{abstract}
Aims: Diabetes is a major public health problem in low and middle-income countries. This study 1) estimated prevalence and factors associated with hyperglycemia in Benin, and 2) assessed the treatment quality of diabetes. Methodology: A cross-sectional research was conducted with two components. The First component has included 4954 subjects aged (18 - 69) randomly selected in Mono/Couffo and Donga regions. Data were collected according to WHO's STEPS approach. Capillary blood glucose was measured using the automat Cardiocheck ${ }^{\circledR}$ PA. The Second component considered Public Health Centers (PHCs) within the study regions. Health system established for diabetes control, healthcare practices and the level of involvement of the Public Healthcare Providers and community actors in the management of diabetes have been explored. Findings: A total of 4775 subjects participated in the first component with a predominance of women $(56.8 \%)$, rural residence and aged ( $<45$ years). Prevalence of hyperglycemia was $9.2 \%$. Age $\geq$ 30 years, Fon ethnic groups and related, obesity, hypercholesterolemia, and inadequate intake of fruits and vegetables were positively associated with hyperglycemia. The second component has underscored a mismatch of facilities, processes and quality healthcare. Conclusion: Diabetes prevalence goes increasingly in Benin when its management is inadequate in PHCs. Prevention and control actions should be strengthened.
\end{abstract}

\section{Keywords}

Diabetes, Determinants, Treatment, Benin 


\section{Introduction}

Diabetes is a seriously chronic disease which occurs with the pancreas failure to produce enough insulin (hormone regulating blood sugar content, or glucose), or when the body fails to use insulin properly that it produces [1]. There are two diabetes types (type I and type II). Type II diabetes represents the majority of diabetes affecting people in the world. It is one of four major non-communicable diseases (NCDs) targeted for global intervention [2]. Type II diabetes occurs in most of the cases as a result of overweight and sedentary lifestyle; it leading to blindness, kidney failure, heart failure, strokes, and lower limbs amputation [1] [3].

Globally, the population of adults living with this disease is estimated to 422 million in 2014, against 108 million in 1980 [2]. Diabetes prevalence has almost doubled since 1980 , increasing from $4.7 \%$ to $8.5 \%$ among the adults. It is reported to having increased much more rapidly in the low and middle-income countries with higher death rates occurring before the age of 70 , while basic screening technologies for diabetes diagnosis and treatment lack in two third of those countries [1] [4]. Moreover, a study carried out in four West African countries (Benin, Burkina-Faso, Guinea and Mali) has clearly shown that the extortionate diabetes treatment costs are generally unaffordable for the modest income populations who, most of the time have subscribed no health insurance [5] [6]. However, the implementation of simple lifestyle and adoption of obesity control interventions, healthy and balanced diet, and regular physical activity may significantly reduce the magnitude of this chronic disease [7] [8] and contribute to deliver the Sustainable Development Goal 3 [9].

In Benin, the 1st National Survey on Non-Communicable Disease Risk Factor (STEPS) in 2008 reported the prevalence of hyperglycemia at $2.6 \%$ but this figure shows a disparity based on the region, sex and living environment [10]. These disparities suggest the need to have as much as possible estimates close to local populations with a view to adapting the appropriate riposte to each context. In this regards, beyond the diabetes prevalence, the provided treatment evaluation is essential to identify those actions already implemented and those to be complemented in order to match the treatment needs with demand, then with the supply.

The Belgian Technical Cooperation supports Benin in NCDs control through the project called "PASS-Sourou". A STEPS survey and treatment quality of major NCDs in the Public Health Centers (PHCs) was initiated in the PASS-Sourou Intervention areas in order to develop an appropriate response scheme. This study has used the data generated during that survey by its first author to 1) estimate prevalence and factors associated with hyperglycemia in adults aged 18 69 , and 2) assess the treatment quality of Type II diabetes in the study areas.

\section{Material and Methods}

\subsection{Scope of the Study}

This study has been simultaneously conducted in Mono, Couffo and Donga re- 
gions of Benin. These are the three regions making up the field of intervention for the Belgian Technical Cooperation's Health Supportive Program referred to as PASS-Sourou. The choice of these departments was based on a set of criteria including high poverty rate, development needs not yet supported by technical and financial partners, political considerations. Both Mono and Couffo Regions are located in the Southwestern part of Benin Republic. According to the Fourth General Population and Housing Census (RGPH4) their populations were estimated respectively to 495,307 and 741,895 inhabitants in 2013 [11]. These two Regions share similar socio-cultural realities with a predominance of Adja ethnic group as well as similar dietary habits. As for Donga Region, it is located in the northern part of Benin, covering the southern zone of the former Atacora Region. In 2013, its population was estimated to 542,605 inhabitants [11]. At the socio-health and community levels, these regions experience the lack of resources in particular, in the areas of medical care, water and electricity access [12].

Benin's health system is pyramidal. It includes national hospitals all located in the city of Cotonou (at central level), Regional Hospitals (at intermediate level) and Zone Hospitals (at peripheral level). Zone Hospital is the first referral level for the peripheral Health Facilities, namely: private health centers, district health centers (DHCs) and Municipal Health Centers (MHCs). The DHCs are equipped with a dispensary run by a nurse. MHCs are led by a physician who also oversees the overall activity of the DHCs [13].

\subsection{Study Design and Recruitment}

This was a cross-sectional, descriptive and analytical study. It has been conducted into two components from October to December, 2015.

\subsubsection{Component I}

\section{1) Population and sampling}

The study population consists of all adults aged 18 - 69, living in Mono, Couffo and Donga Regions for at least six months.

The sample size was calculated based on Schwartz formula [14] taking into account the following parameters: a theoretical prevalence of $50 \%$ risk factors for NCDs, an alpha error risk of $5 \%$ and an accuracy of $6 \%$. The initial size has been later on multiplied by 8 , by considering 8 independent sub-populations along the age group and sex lines. A 5\% increase was made to anticipate the non-respondents cases. Thus, 2499 subjects were selected in Donga Region on the one hand and, the same was done for the Mono/Couffo Regions, on the other hand, making a total of 4998 subjects to be investigated.

A three-stage random sampling technique was performed to select the subjects. The survey sampling made up of all Enumeration Areas (EAs) has been provided by the National Institute of Statistics and Economic Analysis (NISEA) [11]. At the first stage, 125 EAs were selected by a simple random sample without replacement. At the second stage, 20 households have been selected per EA 
by simple random sampling after enumeration of all households in the EA. The selection at the first two stages was carried out in collaboration with INSAE. At the last stage one subject per household was selected according to the KISH method [15].

Excluded from the survey were those subjects who had not consented, those who had two unsuccessful visits, and anyone with a medical condition that prevented the questionnaire from being administered: speech and hearing disorders, major mental disorders.

\section{2) Data collection}

The questionnaire used for the survey is the one developed by the World Health Organization (WHO) for Steps surveys purposes [14]. It consists of 3 parts: Steps 1, 2, 3 and has enabled to collect socio-demographic data; (Step 1), behavioral risk factors (Step 2), and the biological risk factors as well as background information on NCDs among participants (Step 3).

a) Anthropometric measures, food survey, physical activity and blood pressure

The weight of each participant was measured using an electronic scale by 0.1 $\mathrm{kg}$ (model $753 \mathrm{E}, \mathrm{SECA}$, Hamburg, Germany). The height was measured in standing position with a SECA by $0.1 \mathrm{~cm}$. Body Mass Index (BMI) was calculated using the formula BMI $=$ Weight $(\mathrm{kg}) / \mathrm{Height}^{2}\left(\mathrm{~m}^{2}\right)$. Obesity was defined as a BMI $\geq 30 \mathrm{~kg} / \mathrm{m}^{2}$ [16].

The food survey was based on dietary models (standard glass, bowl, standard fruit portions). Harmful consumption of alcohol corresponded to consumption $\geq 6$ standard glasses for men and consumption $\geq 4$ standard glasses for women. Insufficient physical activity was defined according to WHO recommendations, corresponding to less than 30 minutes at a stretch of moderate physical activity (or less than 20 minutes of intense physical activity) at least during 5 days a week [14].

Blood pressure was measured three successive times at a 5-minute interval in sitting position on the left arm after a minimum of 15 minutes rest for the subject and by using Electronic Blood Pressure Monitor (Boso medicus, Germany). The mean of the last two Blood Pressures represented the Systolic and Diastolic Blood Pressures for each subject.

\section{b) Biological measurements}

Blood sugar and cholesterol have been measured on capillary blood using an automation (Cardiocheck PA, PTS Diagnostics ${ }^{\mathrm{TM}}$, USA) provided by WHO at morning after a fasting of at least 8 hours . Hyperglycemia (diabetes) is defined by a fasting blood sugar content $\geq 1.1 \mathrm{~g} / \mathrm{dl}$ according to WHO recommendations for epidemiological investigations [14]. As for hypercholesterolemia, it is defined for a total cholesterolemia $\geq 190 \mathrm{~g} / \mathrm{dl}$ [14].

c) Socio-Economic Status (SES)

A SES score has been calculated based on the education level, major professional occupation and income [17] [18]. Thus, two levels were adopted for each 
of its variables with partial scores of 0 and 1 respectively (education level $\leq$ primary versus education level $>$ primary), (non-remunerated versus remunerated), (income < guaranteed inter-professional minimum wage (GIMW) versus income $\geq$ GIMW (GIMW is $\approx$ US\$80 in 2014)). The overall SES score resulted from the sum of the partial scores of the 3 components (education level, professional occupation and income) and ranged from 0 to 3 . It was divided into two groups based on the median: 0 - 1 (low) and 2 - 3 (high).

3) Statistical analysis

Data entered directly into Personal Digital Assistant (PDAs) were analyzed according to STEPS recommendations using Epi info7 and SPSS Inc. Softwares (CDC Atlanta, USA).

Pregnant women and the physically disabled persons were excluded from the Body Mass Index data analysis. Quantitative variables were expressed as mean and standard deviation. The qualitative ones were presented on their percentages and confidence intervals (CI) at $95 \%$. The proportions were compared with the Khi-2 test; and means were compared using Student's test (normal distributions). In order to improve the representativeness of the sample regarding the overall population in the study regions, the data have been weighted. The weighting factor (weight of each individual) was calculated for each individual based on the product of inclusion probabilities at each stage and a correction factor determined by the number of effectively surveyed households at each stage.

A multiple logistic regression was performed in order to investigate factors associated with hyperglycemia (diabetes). The most significant factors have been defined as variables with $\mathrm{p}$-value $<0.05$.

\subsubsection{Component II}

The second component was qualitative, prospective and retrospective. The study population consisted of public health facilities (PHFs) in the target areas (Regional Hospitals, District Hospitals, Health Centers), their respective Executive Officers, health workers and patients. PHFs were selected based on the stratified multi-stage random sampling. Regional hospitals and Health Zone Hospitals have been systematically selected. In each of the health zones, a simple random sampling of $25 \%$ of the Municipal Health Centers was carried out. In each of the selected municipalities, a simple random sampling of $10 \%$ of the District Health Centers was carried out. In each of the identified health care facilities, the survey targets (health care providers, Health Center Executive Officers and NCDs care beneficiaries) were selected by a rational choice. The diabetes treatment quality in those selected PHFs has been recorded through the dimensions such as "structures", "process of care" and "outcomes" by using the standardized tool designed by WHO [19] for assessing NCDs treatment capacity at the peripheral health centers level, and adapted for the purpose of this study.

Records or data collected from 20 patients admitted for diabetes consultation during the last 12 months were counted. At the level of the health facility, factors 
such as available equipment, personnel and their qualification, clinical and para-clinical examinations, and medicines have been evaluated. The care Process (mainly the clinical examination components, record keeping, number of prescribed medicines, patient follow-up) was also evaluated. The same was carried out for the treatment outcome, mainly the decline of the figures or blood glucose testing or HBP during further visits or hypertension and the satisfaction of patients.

\subsection{Ethical Considerations}

The Research Proposal designed for the study has been approved by the National Ethics Committee for Health Research (NECHR). Authorizations have been gotten from the Commissioners for Health, Medical Chief Executives Officers of health zones, Heads of Districts, and Heads of areas before the survey inception. All the same, each participant in the study has expressed his/her free and informed consent. Participants' personal data were protected and the study team ensured anonymity as regards the sources of collected data.

\section{Results}

\subsection{Component 1}

\subsubsection{Characteristics of the Study Sample}

A total of 4775 subjects were included in this study, representing a $95.5 \%$ response rate. Women dominated the sampling (56.8\%) and adults under 45 years (74\%). The majority of the subjects lived mainly in rural areas (70.0\%) with a low education level (77.8\% had not completed primary education). Most of the participants (79.4\%) were involved in a paid professional activity, but more than 7 out of 10 subjects had low socioeconomic status (Table 1). NCDs behavioral risk factors prevalence was $7.1 \%$ for smoking, $10.6 \%$ for abuse alcohol, $82.4 \%$ for insufficient physical activity and $87.5 \%$ for insufficient consumption of fruits and vegetables. The biological risk factors were: $6.6 \%$ for obesity, $26.8 \%$ for high blood pressure and $14.4 \%$ for hypercholesterolemia.

Table 1. Distribution of hyperglycemia according to socio-demographic characteristics among subjects aged (18 - 69) in Mono/Couffo and Donga in Benin (2015).

\begin{tabular}{cccccc}
\hline & & \multicolumn{3}{c}{ Hyperglycemia } \\
\hline Variables & Frequency & $\%$ & Yes & No & p-value \\
\hline Sex & & & & & \\
Male & 2061 & $43.2 \%$ & $180(8.7)$ & $1881(91.3)$ & \multirow{2}{*}{0.36} \\
Female & 2714 & $56.8 \%$ & $259(9.5)$ & $2455(90.5)$ & \\
Age & & & & & \\
$18-29$ & 1703 & $35.7 \%$ & $102(5.9)$ & $1601(94.1)$ & \\
$30-44$ & 1828 & $38.3 \%$ & $185(10.1)$ & $1643(89.8)$ & $<10^{-4}$ \\
$45-59$ & 931 & $19.5 \%$ & $112(12.1)$ & $819(87.9)$ & \\
$60-69$ & 313 & $6.5 \%$ & $40(12.7)$ & $273(87.3)$ & \\
\hline
\end{tabular}




\section{Continued}

\begin{tabular}{|c|c|c|c|c|c|}
\hline \multicolumn{5}{|l|}{ Residence } & \multirow{3}{*}{0.07} \\
\hline Urban & 1434 & $30.0 \%$ & $149(10.4)$ & $1285(89.6)$ & \\
\hline Rural & 3341 & $70.0 \%$ & $290(8.7)$ & 3051 (91.3) & \\
\hline Education Level & & & & & \multirow{3}{*}{$<10^{-4}$} \\
\hline$<$ Primary & 3713 & $77.8 \%$ & $375(10.1)$ & $3338(89.9)$ & \\
\hline$\geq$ Primary & 1062 & $22.2 \%$ & $64(6.1)$ & $998(93.9)$ & \\
\hline \multicolumn{5}{|l|}{ Income } & \\
\hline$<$ to MGIW/month* & 3969 & $83.1 \%$ & $356(9.01)$ & $3593(90.9)$ & \multirow{2}{*}{0.39} \\
\hline$\geq$ to MGIW/month & 806 & $16.9 \%$ & $83(10.0)$ & 743 (89.9) & \\
\hline \multicolumn{5}{|l|}{ Professional Situation } & \multirow{3}{*}{$<10^{-4}$} \\
\hline Non Remunerated & 983 & $20.6 \%$ & $65(6.6)$ & $918(93.4)$ & \\
\hline Remunerated & 3792 & $79.4 \%$ & $374(9.8)$ & $3418(90.1)$ & \\
\hline \multicolumn{5}{|l|}{ Socio-Economic Status } & \\
\hline Low Level & 3555 & $74.4 \%$ & $282(9.45)$ & $2703(90.5)$ & \multirow{2}{*}{0.62} \\
\hline High level & 1220 & $25.6 \%$ & $110(8.91)$ & $1125(91.0)$ & \\
\hline \multicolumn{5}{|l|}{ Marital Status } & \multirow{3}{*}{0.11} \\
\hline Lives with a Partner & 3981 & $80.4 \%$ & $365(9.5)$ & $3462(90.5)$ & \\
\hline Lives Alone & 973 & $19.6 \%$ & $74(7.8)$ & $874(92.2)$ & \\
\hline \multicolumn{5}{|l|}{ Ethnic Group } & \\
\hline Adja + Fon and Related & 2454 & $51.4 \%$ & $252(10.3)$ & $2202(89.7)$ & \multirow{5}{*}{0.03} \\
\hline Bariba and Related & 1634 & $34.2 \%$ & $139(8.5)$ & $1495(91.5)$ & \\
\hline Fulani & 320 & $6.7 \%$ & $26(8.1)$ & 294 (91.9) & \\
\hline Yoruba & 127 & $2.7 \%$ & $9(7.1)$ & $118(92.9)$ & \\
\hline Others & 239 & $5.0 \%$ & $12(5.0)$ & 227 (94.9) & \\
\hline
\end{tabular}

${ }^{*}$ GIMW guaranteed inter-professional minimum wage/month.

\subsubsection{Prevalence of Hyperglycemia and Associated Factors}

Hyperglycemia prevalence was $9.2 \%$ (95\% CI [7.3 - 11.6]). It was higher in Mono/Couffo regions (10.1\%) than in Donga Region (8.2\%), $\mathrm{p}<0.02$.

- Hyperglycemia and socio-demographic factors

Hyperglycemia was independent of gender, income, residence, socioeconomic and marital status. However, it increased with age $(\mathrm{p}<0.01)$ and more affected poorly educated subjects $(\mathrm{p}<0.001)$, those with remunerated professional activity $(\mathrm{p}<0.001)$, Adja, Fon and other ethnic groups $(\mathrm{p}=0.03)($ Table 1$)$.

- Hyperglycemia and other risk factors for NCDs

Hyperglycemia prevalence was not associated with tobacco consumption, abuse alcohol, insufficient intake of fruits and vegetables, and insufficient physical activity. It is higher among people with hypercholesterolemia $(\mathrm{p}<0.001)$, obesity ( $\mathrm{p}<0.001)$, and those with high blood pressure $(\mathrm{p}<0.001)$ (Table 2$)$.

In multivariate analysis, only age, ethnicity, insufficient intake of fruits and vegetables, obesity and hypercholesterolemia are stable (Table 3 ). 
Table 2. Distribution of hyperglycemia according to non-communicable diseases' other risk factors in subjects aged (18 - 69) in Mono/Couffo and Donga in Benin (2015).

\begin{tabular}{|c|c|c|c|c|c|}
\hline \multirow[b]{2}{*}{ Variables } & \multirow[b]{2}{*}{ Frequency } & \multirow[b]{2}{*}{$\%$} & \multicolumn{3}{|c|}{ Hyperglycemia } \\
\hline & & & Yes & No & p-value \\
\hline \multicolumn{6}{|l|}{ Tobacco } \\
\hline No & 4435 & $92.9 \%$ & $415(9.4)$ & $4020(90.6)$ & 0.15 \\
\hline Yes & 340 & $7.1 \%$ & $24(7.1)$ & $316(92.9)$ & \\
\hline \multicolumn{6}{|l|}{ Alcohol } \\
\hline No & 4271 & $89.4 \%$ & $376(8.8)$ & $3895(91.2)$ & \\
\hline Yes & 504 & $10.6 \%$ & $63(12.5)$ & $441(87.5)$ & 0.06 \\
\hline \multicolumn{6}{|c|}{ Inadequate Consumption of Fruits and Vegetables* } \\
\hline No & 604 & $12.7 \%$ & $46(7.6)$ & $558(92.4)$ & 0.015 \\
\hline Yes & 4171 & $87.3 \%$ & $393(9.4)$ & $3778(90.6)$ & \\
\hline \multicolumn{6}{|c|}{ High Blood Pressure } \\
\hline No & 3493 & $73.2 \%$ & $290(91.7)$ & $3203(8.3)$ & 0,24 \\
\hline Yes & 1282 & $26.8 \%$ & $149(88.4)$ & $1133(11.6)$ & \\
\hline \multicolumn{6}{|c|}{ Obesity } \\
\hline No & 4223 & $93.4 \%$ & $375(8.9)$ & $3848(91.1)$ & 0,036 \\
\hline Yes & 298 & $6.6 \%$ & $53(17.8)$ & $245(82.2)$ & \\
\hline \multicolumn{6}{|c|}{ Hypercholesterolemia } \\
\hline No & 4070 & $85.6 \%$ & $306(7.52)$ & $3764(92.5)$ & $<10^{-4}$ \\
\hline Yes & 685 & $14.4 \%$ & $133(19.42)$ & $552(80.6)$ & \\
\hline \multicolumn{6}{|c|}{ Insufficient Physical Activity ${ }^{* *}$} \\
\hline No & 842 & $17.6 \%$ & $83(9.9)$ & $759(90.1)$ & 0.46 \\
\hline Yes & 3933 & $82.4 \%$ & $356(9.1)$ & 3577 (90.9) & \\
\hline
\end{tabular}

${ }^{*}$ Consumption corresponding to $<5$ portions of fruits and/or vegetables per day. A standard portion equals $80 \mathrm{~g}$. Medium size fruits like an orange, an apple, a banana, a pear counted for one portion. Other fruits like half an avocado, half a large mango also formed one standard portion. Three heaped tablespoons ( $\sim 30 \mathrm{~g}$ per heaped spoon) of cooked vegetables were equal to one portion, and one standard bowl for fresh salad. ${ }^{* *}$ Corresponding to less than 30 minutes at a stretch of moderate physical activity (or less than 20 minutes of intense physical activity) at least during 5 days a week.

Table 3. Factors associated with hyperglycemia among subjects aged (18 - 69) in Mono/Couffo and Donga in Benin (2015).

\begin{tabular}{|c|c|c|c|c|c|c|}
\hline \multirow[t]{2}{*}{ Variables } & \multicolumn{3}{|c|}{ Univariate Model } & \multicolumn{3}{|c|}{ Multivariate Model } \\
\hline & OR & CI & $\mathrm{p}$ & OR & CI & $\mathrm{p}$ \\
\hline \multicolumn{7}{|c|}{ Age (years) } \\
\hline $18-29$ & 1 & & & 1 & & \\
\hline $30-44$ & 2.1 & {$[1.48-2.91]$} & $<10^{-4}$ & 2.2 & {$[1.61-3.17]$} & $<10^{-4}$ \\
\hline $45-59$ & 2.5 & {$[1.63-3.82]$} & $<10^{-4}$ & 2.7 & {$[1.84-4.08]$} & $<10^{-4}$ \\
\hline $60-69$ & 2.6 & {$[1.59-4.44]$} & $<10^{-4}$ & 2.8 & {$[1.68-4.65]$} & $<10^{-4}$ \\
\hline
\end{tabular}




\section{Continued}

\begin{tabular}{|c|c|c|c|c|c|c|}
\hline \multicolumn{7}{|c|}{ Hypercholesterolemia } \\
\hline No & 1 & & & 1 & & \\
\hline Yes & 2.2 & {$[1.41-3.30]$} & $<10^{-4}$ & 2.3 & {$[1.48-3.49]$} & $<10^{-4}$ \\
\hline \multicolumn{7}{|c|}{ Obesity $\left(\mathrm{BMI} \geq 30 \mathrm{~kg} / \mathrm{m}^{2}\right)$} \\
\hline No & 1 & & & 1 & & \\
\hline Yes & 1.6 & {$[1.03-2.44]$} & 0.036 & 1.5 & {$[1.04-2.33]$} & 0.031 \\
\hline \multicolumn{7}{|c|}{ Ethnic Group } \\
\hline Adja + Fon & 1 & & & 1 & & \\
\hline Bariba & 0.5 & {$[0.22-1.03]$} & 0.06 & 0.8 & {$[0.62-1.07]$} & 0.145 \\
\hline Fulani & 0.4 & {$[0.17-0.97]$} & 0.043 & 0.7 & {$[0.41-1.15]$} & 0.16 \\
\hline Yoruba & 0.3 & {$[0.09-0.77]$} & 0.014 & 0.4 & {$[0.19-0.93]$} & 0.033 \\
\hline Others & 0.2 & {$[0.08-0.57]$} & 0.002 & 0.3 & {$[0.14-0.68]$} & 0.004 \\
\hline \multicolumn{7}{|c|}{ Inadequate Consumption of Fruits and Vegetables } \\
\hline No & 1 & & & 1 & & \\
\hline Yes & 1.7 & {$[1.13-2.53]$} & 0.01 & 1.7 & {$[1.13-2.49]$} & 0.011 \\
\hline
\end{tabular}

\subsection{Component 2 (Diabetes Treatment Quality)}

A total of 27 Public Health Facilities participated in the survey: 15 DHCs, 5 MHCs and 7 zone or regional hospitals. In the DHCs, the nursing population ranged from 1 to 2 and those of midwives from 0 to 1 . In the MHCs, there was one Physician with the population of nurses ranging from 2 to 4 , and that of midwives was 1 per center. In the hospitals, the nurses population ranged from 10 to 31, that of midwives from 0 to 1 , Physicians from 2 to 4, and Specialist from 1 to 3 . The most preponderant specialties were gynecology, surgery and pediatrics. There was neither internist doctor, nor diabetologist, nor ophthalmologist, nor cardiologist in the hospitals visited. Similarly, the available caregivers staff operating in those Health centers was generally not trained in NCDs treatment; only $13.3 \%$ to $20.0 \%$ staff has knowledge in the field.

The Health Centers attendance level was relatively higher in the DHCs and MHCs with average monthly consultation frequencies of $324 \pm 229$ and $467 \pm$ 110 versus $242 \pm 173$ for hospitals, respectively. However, Diabetes consultations were scarce, showing a monthly average estimated at 10, mainly in Regional Hospitals/Zone Hospitals (Table 4).

The average fees paid per patient at each visit varied according to both the region and health facility type. In Donga, they were US\$ $(\approx 0.4 \pm 0)$ for the MHCs and DHCs against $(2.07 \pm 0.12)$ and $(4.75 \pm 1.5)$ respectively (for consultations in general medicine and specialized medicine in hospitals. In the Mono/Couffo regions these costs were respectively $0.39 \pm 0.12$ and $0.46 \pm 0.12$ for the DHCs and MHCs against $2.34 \pm 0.46$ and $4.1 \pm 2.69$ for consultations in general medicine and specialized medicines. The practice of insurance was almost non-existent 
Table 4. Monthly consultations in health Centers in Mono, Couffo and Donga Regions in 2015.

\begin{tabular}{cccc}
\hline & Overall & Donga & Mono/Couffo \\
\hline & \multicolumn{2}{c}{ Monthly Consultations } \\
DHCs & $324.7 \pm 229.5$ & $677.8 \pm 215.5$ & $148 \pm 122.21$ \\
MHCs & $467.3 \pm 110.5$ & 473 & $468 \pm 135.2$ \\
HZ/CHD & $242.1 \pm 173.6$ & $184 \pm 181$ & $285.8 \pm 180.1$ \\
& Monthly Consultations for Diabetes & $0(0)$ \\
DHCs & $1 \pm 1(0-2)$ & $1 \pm 1(0-2)$ & 0 \\
CSCOM & 0 & 0 & $13 \pm 13(0-31)$ \\
HZ/CHD & $10.7 \pm 10.7(0-31)$ & $7.7 \pm 6.5(1-14)$ & \\
\hline
\end{tabular}

as only one health center showed this case out of the 27 visited. Consultation, treatment and medication were entirely covered by the patient in the other 26 health centers.

It was noted that equipment such as scale (100\%), measuring rod $(77.7 \%)$ and blood pressure monitor (85.1\%) were available. Glycosuria (53.3\%) in DHCs $80 \%$ in MHCs and $100 \%$ were available in hospitals. Blood sugar measurement was not available in any DHC (0.0\%), but was available in MHCs $(80 \%)$ and hospitals (100\%). Regarding glycated hemoglobin, it is very scarce with $0 \%$ availability in DHCs, $40 \%$ in MHCs and $14.3 \%$ in hospitals. Protocols for treatment of person with diabetes are not available in the DHCs and MHCs as opposed to hospitals. Glibenclamide, oral antidiabetics and level I essential drugs were not available in any DHC. But one noted a contrast by its better availability in MHCs (80\%) as opposed to hospitals (42.9\%). Metformin (oral antidiabetics and level III essential medicines) was not found in any health facility. Insulin injections were available neither in DHCs nor in MHCs. But the availability rate in hospitals was $71.4 \%$ for delayed insulin and $42.9 \%$ for short-acting insulin (Table 5).

Half of the patients had a consultation waiting time of less than 30 minutes, and between 30 minutes and two (2) hours for the other half. This waiting time was relatively shorter in hospitals than in MHCs and DHCs. But $95.8 \%$ of all users surveyed have considered this waiting times as appropriate. There was no evidence available for evaluating the consultations findings. By and large, diabetes treatment was poorly structured and not optimal to match the community participation almost nonexistent in the field.

\section{Discussion}

\subsection{Prevalence of Hyperglycemia}

The overall prevalence of hyperglycemia has been estimated to $9.2 \%$ (95\% CI [7.3 - 11.6]). This prevalence is more than the triple of the national prevalence estimated in the previous STEPS survey in 2008 (2.6\%) and also it does exceed 
Table 5. Components of the structural dimension of diabetes treatment in health Centers in Mono/Couffo and Donga Regions in 2015.

\begin{tabular}{|c|c|c|c|c|c|c|c|c|c|}
\hline \multirow[b]{2}{*}{ Variables } & \multicolumn{3}{|c|}{ DHC } & \multicolumn{3}{|c|}{ MHC } & \multicolumn{3}{|c|}{$\mathrm{ZH} / \mathrm{RH}^{*}$} \\
\hline & $\begin{array}{l}\text { Overall } \\
\mathrm{n}(\%)\end{array}$ & $\begin{array}{l}\mathrm{M} / \mathrm{C} \\
\mathrm{n}(\%)\end{array}$ & $\begin{array}{c}\mathrm{D} \\
\mathrm{n}(\%)\end{array}$ & $\begin{array}{c}\text { Overall } \\
\mathrm{n}(\%)\end{array}$ & $\begin{array}{l}\mathrm{M} / \mathrm{C} \\
\mathrm{n}(\%)\end{array}$ & $\begin{array}{c}\mathrm{D} \\
\mathrm{n}(\%)\end{array}$ & $\begin{array}{l}\text { Overall n } \\
(\%)\end{array}$ & $\begin{array}{l}\mathrm{M} / \mathrm{C} \\
\mathrm{n}(\%)\end{array}$ & $\begin{array}{c}\mathrm{D} \\
\mathrm{n}(\%)\end{array}$ \\
\hline \multicolumn{10}{|c|}{ Availability of Basic Materials (Yes) } \\
\hline Diabetes Protocol & $2(13.3)$ & $0(0.0)$ & $2(40.0)$ & $2(40.0)$ & $0(0.0)$ & $2(100.0)$ & $6(85.7)$ & $4(100.0)$ & $2(66.7)$ \\
\hline $\mathrm{ECI}^{\star \star}$ Material & $1(6.7)$ & $0(0.0)$ & $1(10.0)$ & $0(0.0)$ & $0(0.0)$ & $0(0.0)$ & $1(14.2)$ & $1(25.0)$ & $0(00.0)$ \\
\hline Scale & $14(93.3)$ & $9(90.0)$ & $5(100.0)$ & $5(100.0)$ & $3(100.0)$ & $2(100.0)$ & $7(100.0)$ & $4(100.0)$ & $3(100.0)$ \\
\hline Tape/Ribbon & $13(86.7)$ & $9(90.0)$ & $4(80.0)$ & $4(80.0)$ & $2(66.7)$ & $2(100.0)$ & $7(100.0)$ & $4(100.0)$ & $3(100.0)$ \\
\hline Rod & $11(73.3)$ & $7(70.0)$ & $4(80.0)$ & $5(100.0)$ & $3(100.0)$ & $2(100.0)$ & $7(100.0)$ & $4(100.0)$ & $3(100.0)$ \\
\hline Stethoscope & $14(93.3)$ & $10(100.0)$ & $4(80.0)$ & $5(100.0)$ & $3(100.0)$ & $2(100.0)$ & $7(100.0)$ & $4(100.0)$ & $3(100.0)$ \\
\hline Sphygmomanometer & $12(80.0)$ & $9(90.0)$ & $3(60.0)$ & $5(100.0)$ & $3(100.0)$ & $2(100.0)$ & $7(100.0)$ & $4(100.0)$ & $3(100.0)$ \\
\hline \multicolumn{10}{|c|}{ Availability of Baseline Checkups (Yes) } \\
\hline Blood Sugar Test Strips & $13(86.7)$ & $9(90.0)$ & $4(80.0)$ & - & - & - & - & - & - \\
\hline $\begin{array}{c}\text { Blood Acetone Test } \\
\text { Strips }\end{array}$ & $14(93.3)$ & $9(90.0)$ & $5(100.0)$ & - & - & - & - & - & - \\
\hline Glycosuria & $8(53.3))$ & $4(40.0)$ & $4(80.0)$ & $4(80.0)$ & $3(100.0)$ & $1(50.0)$ & $7(100.0)$ & $4(100.0)$ & $3(100.0)$ \\
\hline Blood Acetone & $3(20.0)$ & $2(20.0)$ & $1(20.0)$ & $2(40.0)$ & $2(66.7)$ & $0(0.0)$ & $6(85.7)$ & $3(75.0)$ & $3(100.0)$ \\
\hline \multicolumn{10}{|c|}{ Availability of Supplementary Basic Records (Yes) } \\
\hline Glycemia & - & - & - & $4(80.0)$ & $3(100.0)$ & $1(50.0)$ & $7(100.0)$ & $4(100.0)$ & $3(100.0)$ \\
\hline Creatininemia & - & - & - & $3(60.0)$ & $2(66.7)$ & $1(50.0)$ & $7(100.0)$ & $4(100.0)$ & $3(100.0)$ \\
\hline Glycated Haemoglobin & - & - & - & $2(40.0)$ & $1(33.3)$ & $1(50.0)$ & $1(14.3)$ & $1(25.0)$ & $0(0.0)$ \\
\hline \multicolumn{10}{|c|}{ Availability of Additional Hospital Records (Yes) } \\
\hline Proteinuria/24h & - & - & - & & & & $4(57.1)$ & $2(50.0)$ & $2(66.7)$ \\
\hline Visual Acuity & - & - & - & & & & $6(85.7)$ & $3(75.0)$ & $3(100.0)$ \\
\hline Ocular Fundus & - & - & - & & & & $5(71.4)$ & $2(50.0)$ & $3(100.0)$ \\
\hline \multicolumn{10}{|c|}{ Availability of Essential Drugs I } \\
\hline Glucose Serum & $8(53.3)$ & $4(40.0)$ & $4(80.0)$ & $5(100.0)$ & $3(100.0)$ & $2(100.0)$ & $7(100.0)$ & $4(100.0)$ & $3(100.0)$ \\
\hline \multicolumn{10}{|c|}{ Availability of Essential Drugs II and Oxygen Device (Yes) } \\
\hline Glibenclamide & - & - & - & $4(80.0)$ & $3(100.0)$ & $1(50.0)$ & $3(42.9)$ & $1(25.0)$ & $2(66.7)$ \\
\hline \multicolumn{10}{|c|}{ Availability of Essential Drugs III （Yes) } \\
\hline Metformine & - & - & - & - & - & - & - & - & - \\
\hline Delayed Insulin & - & - & - & - & - & - & $5(71.4)$ & $2(50.0)$ & $3(100.0)$ \\
\hline Short-Acting Insulin & - & - & - & - & - & - & $3(42.9)$ & $1(25.0)$ & $2(66.7)$ \\
\hline
\end{tabular}

${ }^{\star}$ Zone Hospital/ Regional Hospital, ${ }^{*}$ ECI material: Education Communication and information material.

the estimates made for the three regions in the same survey [10]. This indicates a possible increase in diabetes prevalence among the population liable to significant changes in habits and lifestyle (diet, physical activity, living environment, 
new chemical and physical exposures). The methodological differences regarding age of subjects ( 25 - 65 years in 2008 and 18 - 69 years in 2015), the fraction of screened subjects for diabetes (55.3\% in 2008 [10] and $100 \%$ in this study) and the sampling fluctuations alone cannot substantiate this evolution.

In Africa, this finding is similar to STEPS 2010 data in urban Burkina Faso where hyperglycemia prevalence was 8.5\% [20]. However, lower prevalence rates have been found in other African regions at national level, ranging from $2.1 \%$ in 2015 for Senegal [21]; 2.6\% in 2010 for Togo [22]; 4.3\% for Niger in 2008 [23] and; $4.9 \%$ for Burkina Faso in 2013 [24]. A higher prevalence rate of 15.5\% was found in Democratic Republic of Congo in 2006 [25] and 18.3\% in Chad in 2008 [26]. It is finally comparable to the global diabetes prevalence estimated to $8.5 \%$ in 2014 [1]. This escalating trend of diabetes corroborates the hypothesis regarding the negative impact of rapid urbanization and population's lifestyle shift inducing, in particular, overweight and the sedentary lifestyle favoring the expansion of type 2 diabetes. This high prevalence calls for a closer surveillance and confirmation by supplementary surveys, which enable to understand the possible causes behind this evolution.

\subsection{Factors Associated with Hyperglycemia}

Hyperglycemia prevalence in this study was independent of gender, income, residence, socioeconomic status, and marital status, but it shows an increase with age. Hyperglycemia affects poorer subjects $(\mathrm{p}<0.001)$ and those with paid employment $(p<0.001)$. Trends reported in the literature are highly variable from one study to the other.

The proportion of women suffering from hyperglycemia was statistically higher than that of men in Gabon in 2009 [27], Burkina Faso in 2010 and 2013 [20] [24] while an opposite reality was observed and recorded in Algeria [28], Senegal [21] and Togo in 2010 [22]. Most of these surveys also revealed a significant gap between urban and rural areas [8] [24] [27] [28].

A high prevalence of hyperglycemia in Togo was reported more among retirees [22] than among active people as in our study. The escalating prevalence noticed along the age line has also been objectified in Togo [22] and Burkina Faso [24]. The correlation between hyperglycemia and socio-demographic factors varies across countries but might also possibly be influenced by the methodology and definition of variables. The most consistent observation is mainly related to age: hyperglycemia prevalence increases with age and suggests a longer exposure to risk factors.

This study did not establish a correlation between hyperglycemia prevalence and some other known risk factors for NCDs: tobacco use, alcohol addiction, and low physical activity. However, these factors and more particularly the last two have a significant influence on the prevention of diabetes [2] [3]. The lack of this correlation may be related to the cross-sectional nature of the survey, which does not make it possible to specify whether or not the hyperglycemia predicts 
an exposure to these factors, nor does the possible duration of the study allow.

Similarly, the low prevalence of all these factors has probably not allowed the study to highlight the possible links. On the other hand, with the association of a high hyperglycemia prevalence with obesity $(\mathrm{p}<10-5)$, hypercholesterolemia $(\mathrm{p}<0.001)$ and high blood pressure $(\mathrm{p}<0.001)$ there is, for those subjects, a high risk of prevalence of metabolic syndrome which, according to WHO (1999) is the association of a glucose regulation abnormality with two of the following risk factors: hypertension, dyslipidemia, central or visceral obesity and renal impairment [29].

\subsection{Diabetes Treatment Quality}

The qualitative survey findings have highlighted the crucial problem of inadequate human resources availability in the three regions (Mono/Couffo, Donga). All the same, the limited size of staff available is neither trained nor equipped for carrying out the NCDs diagnosis and treatment, in particular, that of diabetes. This may probably explains the contrast between the high hyperglycemia prevalence among the population and the low number of diabetes cases revealed during consultations. This under-diagnosis situation is also worsened by the lack of awareness on the thematic, the lack of involvement of the populations and especially the absence of organizations for promoting diabetes prevention, screening and treatment. The lack of early diagnosis also sustains the absence of diabetes cases referred to MHCs and DHCs which are rather most of the time driven to hospitals, probably at complication stages. The treatment of cases tested positive will then come up against the low availability of additional tests to assess the impact. Indeed, the recommended minima [30] for the optimal treatment of diabetes at all levels have not been observed in any of the three regions.

However, regarding human resources, the DHCs lack of a Diabetic Educator for the patients as the MHCs do as far as podiatrist and dietician are concerned. Hospitals rather lack internist or diabetes specialist, cardiologist and ophthalmologist who are all essential resources for any integrated comprehensive and quality treatment.

In terms of equipment, the required minima are not met, and are not available with the lack of treatment guide, urine test strips and blood glucose meter appropriate for the DHCs level. In addition to these there should be a tuning fork and reflex hammer, an ophthalmoscope, an optometrist and the biochemistry kit at the MHCs level, followed by fundoscopy, dialysis and cardiovascular diseases testing material at hospital level [30]. These observations confirm that most sub-Saharan African countries do not have a formal organized system for diabetes treatment hence subjects with diabetes are usually treated at both the primary and secondary levels by paramedical caregivers and physicians who are often not adequately trained or lack standard documents to facilitate any standardized care [30] [31]. Besides, diagnostic materials are usually lacking and drugs supply is not assured. Therefore, very few health facilities are equipped for providing a tertiary level comprehensive care [30]. These problems induce a def- 
icit of healthcare provision which does not facilitate any effective assessment of the demand in these centers, overlooking by so doing the financial problem and the socio-cultural constraints which are often identified as the major barrier for the subjects with diabetes to access treatment [32]. The financial challenges are all the more pinpointed as another significant barrier because diabetes treatment cost may vary from $21 \%$ to $70 \%$ depending on the level of its evolution and any possible complications [5] [8].

These results (component 1 and component 2 ) require a greater surveillance for NCDs' risk factors and diabetes in particular through community-based health promotion interventions for behavioral change, as well as government to improve the medical management of diabetes and the establishment of universal health insurance system for poor people.

This study evaluates both the prevalence and the management of diabetes in Benin. It has been conducted in line with WHO's STEPS wise approach following a standardized methodology and using appropriate tools. It has enabled to record a good estimate of hyperglycemia prevalence among the target population and, above all, has facilitated comparison with previous studies produced both in Benin and in Africa and elsewhere. However, the behavioral data collected were declarative, which does enable to get rid of any information bias.

\section{Conclusion}

Hyperglycemia prevalence is high and continues to escalate in Mono, Couffo and Donga regions. It increases along age line and is associated with ethnicity, inadequate fruits and vegetables consumption, obesity and hypercholesterolemia. The currently provided treatment by the system is not adequate. There is also a low awareness and lack of involvement of the population who are not equipped to take charge and participate fully in the organization of a formal system of early detection of diabetes. It is therefore essential to rethink the response in order to strengthen the local health system with a view to effectively tackling diabetes.

\section{Acknowledgements}

The authors hereby express their gratitude to the Benin-Belgian Cooperation, the National Non-Communicable Disease Control Program under the Ministry of Health (Benin), as well as all the subjects who have agreed to participate in this study.

\section{Funding}

This work was supported by the Benin-Belgian Cooperation/Health Sector Supportive Programme-Sourou.

\section{Author Contributions}

MLD designed the study and was principal investigator. DH, KG, MROM, MM 
and PF were involved in the design of the study. SA, PS, RP, AE contributed to patient recruitment, follow up and collection of data. CMA, SA, $\mathrm{CH}$ managed and analyzed data. CMA and SA wrote the first draft of the manuscript. The final manuscript draft was approved by all authors. MLD is the guarantor and has primary responsibility for the integrity of this work as a whole.

\section{Conflicts of Interest}

The authors declare that they have no conflicts of interest.

\section{References}

[1] World Health Organization (WHO) (2016) Global Report on Diabetes. Executive Summary. WHO, Geneva. http://www.who.int/diabetes/global-report/en/

[2] Chan, M. (2015) Noncommunicable Diseases Prematurely Take 16 Million Lives Annually, WHO Urges More Action. WHO, Geneva. http://www.who.int/mediacentre/news/releases/2015/noncommunicable-diseases/e $\underline{\mathrm{n} /}$

[3] WHO (2018) Diabetes Mellitus. Fact Sheet N¹38. WHO, Geneva. http://www.who.int/mediacentre/factsheets/fs138/fr/

[4] WHO (2017) Diabetes. Fact Sheet N³12. WHO, Geneva. http://www.who.int/news-room/fact-sheets/detail/diabetes

[5] Alouki, K., Delisle, H., Besançon, S., Baldé, N., Sidibé-Traoré, A., Drabo, J., et al. (2015) Simple Calculator to Estimate the Medical Cost of Diabetes in Sub-Saharan Africa. World Journal of Diabetes, 6, 1312-1322. https://doi.org/10.4239/wjd.v6.i16.1312

[6] Alouki, K., Delisle, H. and Besançon, S. (2017) [Analysis of Direct Medical Costs of Type 2 Diabetes in Mali]. Revue d'Epidémiologie et de Santé Publique, 65, 41-51. https://doi.org/10.1016/j.respe.2016.06.334

[7] Alouki, K., Delisle, H., Bermúdez-Tamayo, C. and Johri, M. (2016) Lifestyle Interventions to Prevent Type 2 Diabetes: A Systematic Review of Economic Evaluation Studies. Journal of Diabetes Research, 2016, Article ID: 2159890. https://doi.org/10.1155/2016/2159890

[8] Muka, T., Imo, D., Jaspers, L., Colpani, V., Chaker, L., van der Lee, S.J., et al. (2015) The Global Impact of Non-Communicable Diseases on Healthcare Spending and National Income: A Systematic Review. European Journal of Epidemiology, 30, 251-277. https://doi.org/10.1007/s10654-014-9984-2

[9] Mutyambizi, C., Pavlova, M., Chola, L., Hongoro, C. and Groot, W. (2018) Cost of Diabetes Mellitus in Africa: A Systematic Review of Existing Literature. Globalization and Health, 14, 3. https://doi.org/10.1186/s12992-017-0318-5

[10] Houinato, D., Segnon Agueh, J., Djrolo, F. and Djigbenoude, O. (2008) [Final Report of STEPS Survey in Benin]. Ministry of Health, Cotonou. http://www.who.int/chp/steps/2008_STEPS_Report_Benin.pdf

[11] National Institute of Statistics and Economic Analysis (NISEA) (2015) [Fourth General Population and Housing Census (RGPH4)]. NISEA, Cotonou. http://www.insae-bj.org/recensement-population.html?file=files/enquetes-recensem ents/rgph/Resultats_provisoires_RGPH4_2103.pdf

[12] Finoudé, M., Amoussou, R., Acakpo, S., Zountcheme, S., Koukoui, N., Vodungbo, V., et al. (2014) [Health Statistics Yearbook, 2013]. Ministry of Heath, Cotonou. 
http://www.beninsante.bj/documents/Annuaire_2013.pdf

[13] Observatory of Human Resources in Health of Benin (OHRHB) (2013) [Organization of the Health System (Health Pyramid)]. OHRHB, Cotonou.

http://www.sante.gouv.bj/observatoire-rhs/spip.php?article8

[14] WHO (2006) STEPS Manual. WHO, Geneva. http://www.who.int/ncds/surveillance/steps/manual/en/

[15] Berthier, C., Caron, N. and Neros, B. (1998) Kish's Method: The Problems of Drawing and Extrapolation. Stat Meth Series, n89810. INSEE, Paris.

[16] WHO (2009) Global Health Risks. WHO, Geneva. http://www.who.int/healthinfo/global_burden_disease/global_health_risks/en/

[17] Sodjinou, R., Agueh, V., Fayomi, B. and Delisle, H. (2008) Obesity and Cardio-Metabolic Risk Factors in Urban Adults of Benin: Relationship with Socio-Economic Status, Urbanisation, and Lifestyle Patterns. BMC Public Health, 8, 84. https://doi.org/10.1186/1471-2458-8-84

[18] Mizéhoun-Adissoda, C., Desport, J.-C., Houinato, D., Bigot, A., Dalmay, F., Preux, P.-M., et al. (2016) Evaluation of Iodine Intake and Status Using Inductively Coupled Plasma Mass Spectrometry in Urban and Rural Areas in Benin, West Africa. Nutrition, 32, 560-565. https://doi.org/10.1016/j.nut.2015.11.007

[19] WHO (2013) Tools for Implementing WHO PEN (Package of Essential Noncommunicable Disease Interventions). WHO, Geneva. http://www.who.int/ncds/management/pen_tools/en/

[20] Millogo, G.R.C., Yaméogo, C., Samandoulougou, A., Yaméogo, N.V., Kologo, K.J., Toguyeni, J.Y., et al. (2015) Diabetes in Urban Ouagadougou, Burkina Faso: Epidemiological Profile and Level of Perception of the Adult Population. Pan African Medical Journal, 20, 146. https://www.ncbi.nlm.nih.gov/pmc/articles/PMC4613839/

[21] Ministry of Health and Social Action (Senegal) (2016) National Noncommunicable Disease Risk Factor Survey, STEPS 2015. Ministry of Health and Social Action, Dakar.

http://www.ansd.sn/ressources/publications/DV-STEPS-1-06-2016\%20-\%20MF-fin _ANSD\%20vf.pdf

[22] Ministry of Health (2012) Report of the STEPS 2010 Survey in Togo. Non Communicable Disease Services of the Epidemiology Division, Lomé. http://www.who.int/ncds/surveillance/steps/2010STEPS_Report_Togo_FR.pdf

[23] Ministry of Public Health (2008) Noncommunicable Diseases Risk Factors in Niger (WHO "Step Wise" Approach). Directorate for Disease Control and Endemics, Niamey. http://www.who.int/ncds/surveillance/steps/2007_STEPS_Report_Niger.pdf

[24] Ministry of Health (2014) Report of the National Survey on the Prevalence of Major Common Risk Factors for Noncommunicable Diseases in Burkina Faso. Ministry of Health, Ouagadougou.

http://www.who.int/ncds/surveillance/steps/BurkinaFaso_2013_STEPS_Report.pdf? $\underline{\mathrm{ua}}=1$

[25] Ministry of Health, Disease Control Branch (2006) Non-Communicable Disease Risk Factor Survey in Kinshasha, Capital of DR Congo (According to the WHO Steps Approach). Directorate of Disease Control, Kinshasha. http://www.who.int/ncds/surveillance/steps/STEPS_DRC_Final.pdf?ua=1

[26] Ministry of Health, Division of Communicable and Non-Communicable Diseases (2008) Final Report of STEPS Survey in Ndjamena. Division of Communicable and Non-Communicable Diseases, Ndjamena. 
http://www.who.int/ncds/surveillance/steps/2008_STEPS_Report_Chad.pdf?ua=1

[27] Ministry of Public Health and Public Hygiene (2009) Non-Communicable Disease Risk Factor Survey in Libreville and Owendo. Ministry of Public Health and Public Hygiene, Libreville.

http://www.who.int/ncds/surveillance/steps/2009_STEPS_Report_Gabon.pdf

[28] Ministry of Health, Population and Hospital Reform (2005) Directorate of Prevention. Risk Factors for Noncommunicable Diseases in Two Pilot Milayas in Algeria. Directorate of Prevention, Alger.

http://www.who.int/ncds/surveillance/steps/STEPS_Report_Algeria.pdf

[29] WHO (2013) Guidelines for Primary Health Care in Low-Resource Settings, Cancer, Diabetes, Heart Disease and Stroke, Chronic Respiratory Disease. WHO, Geneva. http://www.who.int/nmh/publications/phc2012/en/

[30] International Diabetes Federation, Africa Region. Diabetes Practice Guidelines in Sub-Saharan Africa.

https://www.worlddiabetesfoundation.org/sites/default/files/Type_2_CPG_French_ $\underline{0 . p d f}$

[31] Kapongo, R.Y., Lulebo, A.M., Mafuta, E.M., Mutombo, P.B., Dimbelolo, J.C.M. and Bieleli, I.E. (2015) Assessment of Health Service Delivery Capacities, Health Providers' Knowledge and Practices Related to Type 2 Diabetes Care in Kinshasa Primary Healthcare Network Facilities, Democratic Republic of the Congo. BMC Health Services Research, 15, 9. https://doi.org/10.1186/s12913-015-0679-5

[32] Jaffiol, C. (2011) Diabetes Mellitus in Africa: A Public Health Issue. Bulletin de L'Académie Nationale de Médecine, 6, 1239-1254.

http://www.santetropicale.com/manelec/fr/jdd/download/Diabete_sucre_en_Afriqu e.pdf 